\title{
NUTRIÇÃO E DESENVOLVIMENTO DENTÁRIO
}

\section{NUTRITION AND TOOTH DEVELOPMENT}

\section{Ana Paula Vicente Menolii"; Patrícia Trochman Fanchin ${ }^{1 *}$; Danilo Antônio Duarte $^{2}$; Sylvia Lavinia Ferreira ${ }^{3}$ e José Carlos Pettrossi Imparato ${ }^{2}$}

1* Autor para contato: Centro de Pós-Graduação São Leopoldo Mandic, Campinas, SP, Brasil; (42) 222-4576; e-mail: pfanchin@interponta.com.br e lzoch@terra.com.br

2 Faculdade de Odontologia da USP, São Paulo; e-mails: danilo@fo.usp e jimparato@uol.com.br

3 Universidade de Santo Amaro, São Paulo; e-mail: sylvia@siso.fo.usp.Br

Recebido para publicação em 11/07/2003

Aceito para publicação em 16/10/2003

\section{RESUMO}

Os nutrientes são responsáveis pela síntese de novos compostos vitais para a estruturação das funções celulares. Dessa forma, a nutrição influencia também a formação do órgão dental. Os principais nutrientes envolvidos com a odontogênese são o cálcio, fosfato, as vitaminas A, C, D e o balanço protéico-energético. A vitamina A é responsável pela manutenção da integridade dos tecidos de origem ectodérmica. A vitamina D participa da homeostase do cálcio e do fósforo, interferindo dessa forma na calcificação dentária. A vitamina C é essencial para a função e manutenção da substância intercelular e do colágeno. O fósforo dá maior solidez à estrutura dentária e os lipídios e carboidratos garantem a energia necessária para o processo de odontogênese. A restrição desses componentes pode levar a hipoplasias dentárias, além de distúrbios sistêmicos. Adequações na dieta da gestante e durante o primeiro ano de vida da criança são necessárias para prevenir tais defeitos.

Palavras-chave: nutrição, odontogênese, desenvolvimento dentário, hipoplasia de esmalte

\section{ABSTRACT}

Nutrients are responsible for the sinthesis of new vital compounds for the structuralization of celular functions. Thus, nutrition also influences the formation of the teeth. The main nutrients involved in odontogenia are calcium, phosphate, vitamins A, C , D and the protein/energy balance. Vitamin A is responsible for the sustenance of the integrity of ectodermic tissues. Vitamin D facilitates calcium and phosphorus homeostasis, interfering in dental calcification. Vitamin C is essential to the maintenance and functioning of intercelular substances and collagen. Phosphorus adds solidity to the dental structure and lipids and carbohydrates ensure the energy 
needed in odontogenia. The lack of these elements may lead to dental hypoplasia, as well as to systemic disturbances. It is necessary to make adjustments in the pregnant woman's diet and also in the infant's diet during his/her first year, in order to prevent such deficiencies.

Key words: nutrition, odontogenia, tooth development, enamel, hypoplasia

\section{Introdução}

O termo nutrição significa o conjunto de processos que vão desde a ingestão de alimentos até sua assimilação pelas células. Substâncias nutritivas são convertidas em energia útil, calor e trabalho de síntese de novos compostos vitais para a estruturação das funções celulares, que visam por fim, a construção e destruição dos tecidos. Também as células formativas do órgão dental requerem energia e nutrientes especiais para sua fisiologia normal (Bezerra e Toledo, 1997; Franco, 1998; Auad e Pordeus, 1999).

Os efeitos sistêmicos provenientes da nutrição podem alterar o desenvolvimento dos dentes, a qualidade e quantidade da saliva e afetar o sistema imunológico (Bezerra e Toledo, 1997).

Em animais, estão bem documentados em vários trabalhos, os efeitos da inadequada nutrição sobre a erupção e desenvolvimento dentário. Em ratos, a nutrição indevida reduz o fluxo e composição salivar e altera o sistema imunológico, tornando o esmalte mais suscetível à cárie (Alvarez e Navia, 1989; Alvarez et al. 1993). Esses estudos experimentais com animais suportam a hipótese de que, em seres humanos, os distúrbios na nutrição têm um efeito significante na formação dental pela interferência no desenvolvimento celular, formando um esmalte hipoplásico, estrutura essa mais suscetível à cárie.

Alvarez et al. (1990), em um estudo transversal com 1481 crianças observaram relação positiva entre nutrição deficiente e cárie em dentes decíduos. Em 1995, Alvarez, agora com um estudo longitudinal de 4 anos envolvendo 209 crianças peruanas, constatou que episódios de má nutrição ocorridos no primeiro ano de vida estão associados à alta ocorrência da doença cárie em dentes decíduos e permanentes, muitos anos depois. Infante e Gillespie (1976) notaram uma forte correlação entre nutrição indevida, hipoplasia de esmalte e ocorrência de cárie em dentes decíduos.

Este artigo busca na literatura a relação entre aspectos nutricionais e a formação e desenvolvimento dental, possibilitando ao cirurgião-dentista uma melhor compreensão da influencia dos fatores nutricionais nos processos de odontogênese e na ocorrência de alterações dentárias.

\section{Revisão da Literatura}

Os fatores nutricionais indubitavelmente exercem um papel crítico no desenvolvimento de dentes decíduos devido ao período relativamente curto de mineralização desses dentes quando comparados aos permanentes (Alvarez e Navia, 1989).

A amelogênese é caracterizada por dois processos distintos: formação da matriz orgânica e sua subseqüente mineralização. Os ameloblastos começam a secretar a matriz orgânica em uma fina camada próximo à dentina, pouco depois que a deposição de dentina tenha começado. A mineralização do esmalte ocorre na matriz e na substância interprismática e é caracterizada pela presença de numerosos cristais de apatita. Essa mineralização inicial é rapidamente seguida por um segundo estágio, ou maturação, no qual os cristais aumentam de tamanho. Se a deficiência nutricional ocorre logo no início da formação da matriz orgânica, a expressão clínica pode ser hipoplasia de esmalte, caracterizada por rugosidades e ausência de esmalte. Se, porém, ocorre posteriormente, durante o processo de maturação, o resultado pode ser uma hipocalcificação expressa por manchas brancas, circundadas por esmalte normal (Alvarez e Navia, 1989).

Os principais nutrientes envolvidos com a 
odontogênese são cálcio, fosfato, vitaminas A, C, D e o balanço protéico-energético (Auad e Pordeus, 1999).

A vitamina $A$, também conhecida como retinol, acha-se relacionada com os processos de crescimento e desenvolvimento normais dos tecidos ósseos e dentários e exerce papel importante na manutenção da integridade de todas as células epiteliais do organismo. Os sinais e sintomas de deficiência de vitamina A caracterizam-se por alterações em órgãos e tecidos de origem ectodérmica, incluindo-se aí o órgão dental (Franco, 1998). A deficiência de vitamina A é conhecida por alterar a amelogênese, a dentinogênese e a função imunológica. Reduz ainda a síntese de glicoproteínas salivares específicas para a aglutinação de bactérias (Bezerra e Toledo, 1997).

Os alimentos que contêm a vitamina A préformada são fígado e rim de animais terrestres e aquáticos, leite integral, creme de leite, queijos, manteiga, peixes e gema de ovo (Franco, 1998).

Para as crianças lactentes, a quantidade de retinol suficiente é aquela relacionada com o leite humano. Para as crianças de 6 meses até 1 ano de idade, as necessidades são de 400 microgramas de retinol (Franco, 1998).

A vitamina $\mathrm{D}$ age como um dispositivo regulador na homeostase do fósforo e do cálcio, interferindo dessa forma na calcificação dentária. Sob a denominação genérica de vitamina D são incluídas várias substâncias que podem ser ativadas pela exposição aos raios ultravioletas. Essas substâncias são chamadas de pró-vitaminas D. Já foram identificados 11 compostos com atividade vitamina D, mas os mais importantes são o calciferol e o colecalciferol. O fígado é o local de transformação da vitamina D em seu derivado 25-hidroxicolecalciferol, que é a maior forma circulante da vitamina D. (Franco, 1998).

A forma ativa da vitamina $\mathrm{D}$ acredita-se agora ser o calcitriol, que parece ser a forma ativa da vitamina D3 para o processo de absorção e deposição do cálcio, que é influenciado pelos processos de absorção intestinal, metabolismo ósseo e excreção renal da vitamina $\mathrm{D}$ e especialmente pelos hormônios paratireoidianos e calcitriol (Franco, 1998; Raiten et al., 1998). O paratormônio atua retirando o cálcio dos ossos e transferindo-o para os canalículos epifisários, daí resultando a hipercalcificação dos ossos e dentes.

Existem opiniões divergentes quanto ao mecanismo de absorção do cálcio. De acordo com pesquisas in vitro, sua absorção para ser um processo diretamente ativo em oposição a um gradiente elétrico depende de um metabolismo oxidativo, influenciado pela vitamina D (Schachter, 1964). O principal efeito dessa vitamina é o de incrementar a permeabilidade das membranas celulares para os íons cálcio. (Harrison e Harrison, 1941)

Tem sido também demonstrado que a acidificação do $\mathrm{pH}$ intestinal facilita a absorção do cálcio, provavelmente por conversão do cálcio alcalino, pouco solúvel, em formas ácidas mais facilmente solúveis. Na ausência da vitamina D a absorção do cálcio é drasticamente reduzida. Com a inadequada absorção do cálcio, há sua mobilização de depósitos ósseos que pode conduzir, especialmente em crianças, a sérias doenças ósseas metabólicas, como o raquitismo (Franco, 1998).

Os mecanismos do metabolismo do cálcio podem ser englobados em dois pares de balanços: absorção e excreção, deposição e mobilização. A absorção do cálcio acha-se relacionada com a ingestão de proteínas e glicídios. Uma dieta rica em proteínas promove uma absorção de 5\% de cálcio. Quanto aos glicídios, a lactose parece aumentar a absorção do cálcio, principalmente no íleo, pela atuação de lactobacilos produtores de ácido lático que aumenta o pH intestinal. A única fonte de lactose é o leite, que é uma das maiores fontes nutricionais de cálcio (Franco, 1998).

Os lipídios também exercem influência sobre a absorção do cálcio, o que se traduz na diminuição do cálcio utilizável pelo organismo.

As melhores fontes de cálcio são os queijos, outras são o leite, o melado e alguns vegetais como brócolis, mandioca, milho e tremoço. Uma excelente fonte econômica de cálcio é a casca de ovo de galinha, higienizada, dessecada e reduzida a pó. Pode então ser usada em mingaus, sopas e outras preparações culinárias (Franco, 1998).

Um outro fator importante que interfere nas 
concentrações de cálcio é o sódio, não existindo, porém, estudos com longo tempo de acompanhamento. Alguns estudos com humanos demonstram que alterações na ingestão estão associadas com alterações na excreção do cálcio e do metabolismo ósseo (Chan et al., 1992; Massey e Whiting, 1996).

Chan e Swaminathan (1998) desenvolveram um estudo de acompanhamento mais prolongado com ratos divididos em grupos, com diferentes concentrações de sódio na dieta. Observaram que quanto maior a ingestão de sódio, maior a perda de cálcio via urina e conseqüente perda óssea, levando à osteoporose. Talbott et al. (1998), também demonstraram, através de pesquisas com animais, que há elevados níveis de reabsorção óssea quando a amostra é submetida a dieta pobre em cálcio. Shapses et al. (1995) mencionaram que a ingestão de quantidades inadequadas de cálcio leva à reabsorção óssea e aumenta o risco de desenvolver osteoporose.

Durante a gravidez e período de amamentação foi observado por Donangelo et al. (1996) que há ajustes (ósseo e renal) para manter a homeostase do cálcio.

A vitamina C é também conhecida como ácido ascórbico ou ácido cevitâmico, exercendo importante papel na síntese de catecolaminas e corticóides. Participa na síntese e manutenção dos tecidos e apresenta ação na formação de ossos, dentes e sangue (Franco, 1998).

Sobre a odontogênese, sua participação está relacionada ao metabolismo da tirosina, e na síntese de hidroxiprolina e substância cimento, necessários para formação do colágeno. Essa vitamina é essencial para a função e manutenção da substância básica intercelular e do colágeno. No estado de deficiência, os feixes de colágeno no cimento intercelular desaparecem e a substância básica colágena despolimeriza-se e aparece delgada e aquosa. Como a substância básica é essencial à matriz do tecido conjuntivo e de outros constituintes efetivos da armação dos tecidos, a deficiência de vitamina $\mathrm{C}$ concorre para a extensão das lesões (Franco, 1998).

Na fase de deficiência, em crianças, ocorre parada das funções osteoblástica e odontoblástica, o que resulta em retardamento do crescimento ósseo e da dentição, sendo a dentina reabsorvida e atrofiada. A degeneração dos odontoblastos ocorre na polpa (Franco, 1998).

O metabolismo do fósforo acha-se intimamente ligado ao do cálcio e $80 \%$ de seu conteúdo no organismo encontra-se no esqueleto e nos dentes. Sua absorção é regulada pela vitamina D e seu metabolismo associado ao paratormônio. O paratormônio aumenta a calcemia e diminui o fósforo sangüíneo, aumentando a excreção de ambos. Presente na estrutura de ossos e dentes confere-lhes maior solidez (Franco, 1998).

A odontogênese é também influenciada pelo balanço protéico-energético. Guyton e Hall (1997) observaram que nesse processo, cerca de 20 a 30 gramas de proteínas corporais são degradadas diariamente e utilizadas para a produção de energia, fenômeno conhecido como "perda obrigatória de proteínas”. Entretanto, as proteínas não constituem a principal fonte energética para o organismo, papel desempenhado por lipídios e carboidratos, que por isso são conhecidos como "poupadores de proteínas”. Em situações em que a ingestão de carboidratos e lipídios é insuficiente para prover o aporte energético necessário ao desenvolvimento das funções fisiológicas, inicia-se um processo de degradação protéica, em alguns casos atingindo cerca de $125 \mathrm{~g} /$ dia, com deterioração acentuada em todas as funções celulares.

\section{Discussão}

Todas as etapas do crescimento, incluindo a odontogênese, dependem da presença da quantidade de nutrientes apropriada à construção celular e formação de enzimas. O efeito da falta de nutrientes adequados depende da velocidade de instalação, severidade e duração da deficiência (Krause e Mahan, 1995).

Uma nutrição deficiente, em certos períodos do desenvolvimento é mais prejudicial do que em outras épocas e o período fetal parece ser muito vulnerável, por isso o aporte nutritivo e o estado nutricional da mãe durante a gravidez são muito importantes. Alguns ajustes dietéticos precisam ser feitos. (Krause e Mahan, 1995). A Comissão de Nutrição e Alimentos do Conselho Nacional de Pes- 
quisa sugere que se somem $30 \mathrm{~g}$ de protéinas além das 0,8 por kilo de peso corpóreos habituais. Se forem alcançadas as necessidades de proteínas, todos os outros nutrientes, exceto o ácido ascórbico e vitaminas A e D serão fornecidos, devido a sua associação com proteínas nos alimentos. Se a proteína for insuficiente na dieta da gestante, então cálcio, fósforo, ferro e vitaminas do complexo B também o serão. As necessidades adicionais de proteínas, calorias e cálcio podem ser supridas pela ingestão de 1 litro de leite desnatado.

O cálcio é um dos elementos mais importantes da dieta da mulher grávida e um suprimento adequado de vitamina D é essencial para a utilização do cálcio e fósforo necessários para a calcificação dos ossos e dentes fetais, assim como para as próprias necessidades da mulher grávida. Apesar das evidências mostrarem que a absorção do cálcio aumenta durante a gravidez e lactação, a necessidade diária de cálcio deve ser aumentada de 0,8 gramas para 1,2 gramas a fim de satisfazer as necessidades adicionais. Prentice (1998), discorda dessa informação. Através de uma revisão da literatura com quatro estudos desenvolvidos em várias partes do mundo, constatou que não há necessidade de suplementação de cálcio durante a amamentação e que a concentração de cálcio no leite materno não é influenciada pela ingestão de cálcio pela mãe durante esse período. A autora concluiu que as recomendações correntes e tão comuns nos dias de hoje sobre a suplementação de cálcio do lactente durante a amamentação são infundadas. Já Krause e Mahan (1995) afirmaram que a mulher deve beber uma quantidade extra de leite e ser exposta ao sol para que as necessidades de vitamina $D$ sejam satisfeitas. Se as necessidades de cálcio e vitamina D forem supridas, provavelmente as de fósforo também serão. Na infância, até os 6 meses de idade, o leite contribui com todas as calorias necessárias. Aos 6 meses ele fornece de 50 a $60 \%$ das calorias. Cereais, legumes, frutas, carnes e ovos, quando introduzidos, suprem as demais necessidades calóricas.

Segundo a Organização Mundial de Saúde, a demanda de vitaminas e minerais também aumenta nesse período, embora se discutam as quantidades exatas (Akré,1994). Segundo STEWART et al. (1982) uma deficiência nutricional, especialmente de vitaminas $\mathrm{A}, \mathrm{C}$ e $\mathrm{D}$ podem causar defeitos na formação da matriz do esmalte.

A vitamina D promove absorção do cálcio e fósforo do trato intestinal. Uma dieta deficiente em vitamina $\mathrm{D}$ produz um balanço negativo do cálcio no organismo, que leva a uma menor mineralização óssea. Uma vez que a matriz orgânica dos ossos e da dentina são similares, é esperada uma hipomineralização da dentina em crianças com deficiências nutricionais severas de vitamina D. Segundo Stewart et al. (1982), ratos alimentados com dieta pobre em vitamina $\mathrm{D}$, mostram uma maior extensão da camada de pré-dentina, irregularidades na mineralização pela desorganização de odontoblastos e marcado decréscimo de atividade da fosfatase alcalina em germes dentários.

Segundo Pinkham et al. (1996) as hipoplasias de esmalte são atualmente descritas como do tipo ambiental e localizada. O tipo ambiental refere-se à patologia que segue um padrão cronológico linear de formação do esmalte, comprometendo vários dentes que estão sendo formados ao mesmo tempo e está associada a desordens sistêmicas como prematuridade, baixo peso ao nascimento, problemas respiratórios graves, deficiências nutricionais, hipocalcemia neonatal e alguns distúrbios no organismo materno. Apesar da diversidade, agem através de um mecanismo de ação comum de decréscimo de reservas minerais, especialmente de cálcio e fósforo, que pode afetar a mineralização dos tecidos dentais diretamente (Menoli et al. 1998).

Mellanby apud Freire (2000), já em 1918 demonstrou que a restrição de vitamina D causava hipoplasia de esmalte dentário em cães. Em 1923, relacionou a deficiência de vitamina D com hipoplasia de esmalte em crianças britânicas. Freire (2000) ressalta que embora naquela época as conclusões apresentadas por Mellanby tenham sido refutadas por outros pesquisadores, estudos mais recentes confirmam que a hipocalcemia do recém-nato, causada por deficiência de vitamina $\mathrm{D}$, são reconhecidas como causas de hipoplasia de esmalte.

Segundo Corrêa et al. (1997) a alteração metabólica no complexo vitamina D-cálcio-fósforo pode produzir efeitos sistêmicos conhecidos por raquitismo. Nessa patologia, o crânio apresenta projeção frontal e occipital e a cabeça exibe um aspec- 
to quadrado. Há protrusão anterior do externo conhecido como "peito de pombo". Pode ocorrer arqueamento lateral das pernas e baixa estatura. As alterações dentárias no raquitismo incluem a ampliação da câmara pulpar e do canal radicular. A dentina é fina, com largos glóbulos anormalmente calcificados, separados por largas zonas irregulares de dentina interglobular.

É importante ressaltar que uma nutrição adequada na gravidez, lactação e primeiros anos de vida do bebê constitui-se um dos principais determinantes da saúde e do bem estar do ser humano (Ferreira e Osmo,1998).

Para a gestante, segundo Krause e Mahan (1995), é aconselhável um ganho de peso de 0,7 a 1,3 quilos durante o primeiro trimestre e um ganho de 0,35 quilos por semana durante o restante da gravidez. As necessidades dietéticas recomendadas para o período de gravidez e lactação são expressas na tabela 1 e o padrão alimentar diário para assegurar uma nutrição adequada durante a gravidez é apresentado na tabela 2 .

Para o recém-nato, conforme enfatiza a Organização Mundial de Saúde (OMS), o leite materno deve ser oferecido de forma exclusiva até os 6 meses de vida. O único nutriente do qual o leite materno não supre as necessidades do lactente é a vitamina $\mathrm{D}$, que existe em pequenas quantidades no leite e cuja formação cutânea, por irradiação de luz ultravioleta solar, não se faz em proporções adequadas. Portanto, recomenda-se a introdução de um suplemento de vitamina $\mathrm{D}$ a partir do primeiro mês de vida, nas doses profiláticas de 400 a 800 UI/dia (Ferreira e Osmo, 1998).

\section{Conclusões}

- Os principais nutrientes envolvidos com a odontogênese são o cálcio, o fósforo, as vitaminas A, C e D e o equilíbrio protéico-energético; a restrição desses nutrientes pode levar a hipoplasias dentárias e distúrbios sistêmicos;

- Ajustes dietéticos precisam ser feitos durante a gestação para equilibrar o estado nutricional da mãe, bem como para o lactente, perdurando especialmente durante todo o primeiro ano de vida, a fim de se prevenir defeitos de formação na matriz do esmalte.

Tabela 1 - Necessidades dietéticas recomendadas para a gestante

\begin{tabular}{|c|c|c|c|c|}
\hline & \multicolumn{3}{|c|}{ MULHERES NÃO GRÁVIDAS } & \multirow[b]{2}{*}{ lactação } \\
\hline & 19 a $22 \mathrm{a}$ & 23 a 50 a & gravidez & \\
\hline Energia (kcal) & 2100 & 2000 & +300 & +500 \\
\hline Proteína (q.) & 46 & 46 & +30 & +20 \\
\hline Vitamina A (U.I.) & 4000 & 4000 & 5000 & 6000 \\
\hline Vitamina D (U.I.) & 400 & & 400 & 400 \\
\hline Vitamina E (U.I.) & 12 & 12 & 15 & 15 \\
\hline Vitamina C (mg.) & 45 & 45 & 60 & 80 \\
\hline Vitamina $B_{6}$ (mg.) & 2.0 & 2.0 & 2.5 & 2.5 \\
\hline Vitamina $\mathrm{B}_{12}$ (mcg.) & 3 & 3 & 4 & 4 \\
\hline Cálcio (mg.) & 800 & 800 & 1200 & 1200 \\
\hline Fósforo (mg.) & 800 & 800 & 1200 & 1200 \\
\hline lodo (mcg.) & 100 & 100 & 125 & 150 \\
\hline Ferro (mg.) & 18 & 18 & + & 18 \\
\hline Magnésio (mg.) & 300 & 300 & 450 & 450 \\
\hline Zinco (mg.) & 15 & 15 & 20 & 25 \\
\hline
\end{tabular}

Fonte: Krause e MahanFonte: KRAUSE e MAHAN, 1995., 1995. 
Tabela 2 - Padrão alimentar diário para assegurar uma nutrição ideal durante a gravidez

\begin{tabular}{lcc}
\hline \multicolumn{1}{c}{ ALIMENTO } & QUANTIDADE & PROTEÍNA (g.) \\
\hline Leite integral & 3 ou 4 copos de $120 \mathrm{ml}$ & 24 a 32 \\
Carne magra, aves, peixe, queijo & 2 porções/dia, totalizando $120 \mathrm{~g}$. & 28 \\
Ovo & Um & 7 \\
Frutas & Pelo menos 2 porções de frutas cítricas & 1 \\
Batata & $\quad$ ( 1 porção = 1 laranja média) \\
Vegetais cozidos ou crus & Uma de tamanho médio & 3 \\
Pão e cereais & 2 ou + porções ( 1 porção = 1/2 xícara) & 4 \\
Manteiga ou margarina & 3 a 4 porções ( 1 porção = 1 fatia de pão) & 6 a 8 \\
Vitamina D & 1 colher de sopa & \\
TOTAL & 400 U.l. = 1 litro de leite fortificado & 73 a 83 \\
\hline
\end{tabular}

Fonte: Krause e Mahan, 1995.

\section{REFERÊNCIAS}

1 AKRÉ, J. (ed.) Alimentação infantil - bases fisiológicas. Genebra: Organização Mundial da Saúde, 1994. 95p.

2 ALVAREZ, J.O. Nutrition, tooth development and dental caries. Am J Clin Nutr, Bethesda, v.61, n.2, p.410-416, Feb.1995.

3 ALVAREZ, J.O.; CACEDA, J.; WOOLLEY, T.W.; CARLEY, K.W.; BAIOCCHI, N.; CARAVEDO,L. A longitudinal study of the dental caries in the primary teeth of children who suffered from infant malnutrition. J Dent Res, Indianapolis, v.72, n.12, p.1573-1576, Dec. 1993.

4 ALVAREZ, J.O.; EGUREN, J. C.; CACEDA, J.; NAVIA, J.M. The effect of nutritional status on the age of distribution of dental caries in the primary teeth. J Dent Res, Indianapolis, v.69, n.9, p.1564-1566, Sept.1990.

5 ALVAREZ, J.O., NAVIA, J.M. Nutritional status, tooth eruption and dental caries: a review. Am J Clin Nutr, Bethesda, v.49, n.3, p.417-426, Mar.1989.

6 AUAD, S.M.; PORDEUS, I.A. Nutrição e sua influência nos processos de odontogênese, erupção e desnvolvimento da cárie dentária. Revista do CROMG, Belo Horizonte, v.5, n.3, p.151-155, set./dez.1999.
7 BEZERRA, A.C.B.; TOLEDO, O.A. Nutrição, dieta e cárie. In: KRIEGER, L. (coord.). ABOPREV: promoção de saúde bucal. São Paulo: Artes Médicas, 1997. Cap.3, p.43-67.

8 CHAN, E.L.P.; SWAMINATHAN, R. Calcium metabolism and bone calcium content in normal and oophorectomized rats consuming various levels of saline for 12 months. J Nutr, Bethesda, v.128, n.3, p.633-639, Mar. 1998.

9 CHAN, E.L.P.; HO, C.S.; MAC DONALD, D.; HO, S.C.; CHAN, T.Y.; SWAMINATHAN, R. Interrelationships between urinary sodium, calcium, hidroxipoline and serum PTH in healthy subjects. Acta Endocrinol, Copenhague, v.127, n.3, p.242-245, Sept.1992.

10 CORRÊA, M.S.N.P.; CAIXETA, F.F.; TEODORO, M.G.; AZEVEDO, A.M. Raquitismo: revisão de literatura e relato de um caso clínico. Ver Assoc Paul Cir Dent, São Paulo, v.51, n.3, p.237-241, mai.jun. 1997.

11 DONANGELO, C.M.; TRUGO, N.M.F.; MELO, G.J.O.; GOMES, D.D.; HENRIQUES, C. Calcium homeostasis during pregnancy and lactation in primiparous and multiparous womwn with sub-adequate calcium intake. Nutrition Research, St. John's , v.16, n.10, p.1631-1640, Oct. 1996. 
12 FERREIRA, F.P.; OSMO, A.A. Nutrição da criança. In: CORRÊA, M.S.N.P. Odontopediatria na primeira infância. São Paulo: Santos, 1998. Cap. III, p.23-31.

13 FRANCO, G. Tabela de composição química de alimentos. 9.ed. São Paulo: Atheneu,1998. 307p.

14 FREIRE, M.C.M. Dieta, saúde bucal e saúde geral. In: BUISCHI, Y.P. Promoção de saúde bucal na clínica odontológica. São Paulo: Artes Médicas, 2000. Cap. 10, p.248-278.

15 GUYTON, A.C.; HALL, J.E. Tratado de fisiologia médica. 9.ed. Rio de Janeiro: Guanabara Koogan, 1997.1014p.

16 HARRISON, H.E.; HARRISON, H.C. The renal excretion of inorganic phosphate in relation to the action of vitamin D and parathyroid hormone. J Clin Invest, Nova York, v.20, p.47-55,1941.

17 INFANTE, P.F.; GILLESPIE,G.M. Dental caries experience in the deciduous dentition of rural guatemalan children ages 6 months to 7 years. J Dent Res, Indianapolis, v.55, p.951-957, Nov./Dez.1976.

18 KRAUSE, M.V.; MAHAN, L.K. Alimentos, nutrição e dietoterapia. 8.ed. São Paulo: Roca,1995. 1157p.

19 MASSEY, L.K.; WHITING, S.J. Dietary salt, urinary calcium and bone loss. J Bone Miner Res, Durham, v.11, n.6, p.731-736, June.1996.

20 MENOLI, A.P.V.; MELO, M.M.; WALTER, L.R.F. Complicações dentais associadas à intubação orotraqueal e laringoscopia. J Bras Odontop Odonto Bebe, Curitiba, v.1, n.1, p.9-14, jan./mar., 1998.

21 PINKHAM, J.R.; CASAMASSIMO, P.S.; MCTIGUE, D.J.; FIELDS, H.W.; NOWAK, A. Odontopediatria - da infância à adolescência. 2.ed. São Paulo: Artes Médicas, 1996. 661p.

22.PRENTICE, A. Calcium requirements of breast-feeding mothers. Nutrition Reviews, Washington, v.56, n.4, p.124130, Apr., 1998.

23 RAITEN, D.J.; TALBOT, J.M.; WATERS, J.H. Assesment of nutrient requirements for infant formulas: minerals. J Nutr, Bethesda, v.128, n.115, p.2140-2161, Nov., 1998.

24 SCHACHTER, D. Metabolism of vitamin D1, preparation of radioactivily vitamin $\mathrm{D}$ and its intestinal absorption in the rat. J Clin Inv, Nova York, v.43, p.787-796, 1964.

25 SHAPSES, S.A.; ROBINS, S.P.; SCHWARTZ, E.I.; CHOWDHURY, H. Short-term changes in calcium but not protein intake alter the rate of bone resorption in healthy subjects as assessed by urinary pyridinium cross-link excretion . J Nutr, Bethesda, v.125, n.11, p.2814-2821, Nov.1995.

26 STEWART, R.E.; BARBER, T.K.; TROUTMAN, K.C. Pediatric dentistry - scientific foundations and clinical practice. St. Louis: Mosby, 1982. 1012p.

27 TALBOTT, S.M.; ROTHKOPF, M.M.; SHAPSES, S.A. Dietary restriction of energy and calcium alters bone turnover and density in yonger and older female ras. J Nutr, Bethesda, v.128, n.3, p.640-645, Mar. 1998. 